\title{
Peritoneal vaginoplasty by Luohu I and Luohu II technique: a comparative stuc. of the outcomes
}

\author{
Aiwen Le ${ }^{1}$, Zhonghai Wang ${ }^{1 *}$, Lili Shan ${ }^{1}$, Tianhui Xiao ${ }^{1}$, Rong Zhuo ${ }^{1}$ and Guangnan L( ${ }^{2}$
}

\begin{abstract}
Background: Surgical vaginoplasty is the standard treatment for women suffering th Mayer-Rokitansky-KüsterHauser (MRKH) syndrome. This study compares the advantages and disad vant ges of Luohu I technique or its modification, Luohu II technique.

Methods: Women with MRKH syndrome undergoing laparoscopic neritonea áginoplasty using either the Luohu I ( $N=145)$ or Luohu II $(N=155)$ technique were recruited. We comfan affectiveness of the Luohu II and one of Luohu I. Sexual satisfaction was checked by Female Sexual Function In aex.

Results: There was no significant difference in the mean oneration time, volume of intraoperative blood loss, time for the first passage of gas, sexual satisfaction (and hospita' stay. patients in either group $(P>0.05)$. But patients in the Luohu II group had a significantly lower incidence of co licat ns than patients in the Luohu I group. All patients had vaginal depths more than $9 \mathrm{~cm}$ over 3 montb sost-s

Conclusions: Compared with the traditional ka. 1, easier to perform and causes less damage to the bic de/and rectum. The physiological and anatomical features of the artificial vagina resemble the normal sa. a in bokn techniques.
\end{abstract}

Keywords: MRKH syndrome, Vaginorlissty, Per Yeum, Laparoscope

\section{Background}

Artificial vaginoplasty is wic used to treat MayerRokitansky-Küster-Hauser ( $\mathrm{R}_{\mathrm{N}} \mathrm{r}_{3}$, syndrome, a congenital disorder char ized aplasia of the uterus and the upper par $f t$ gina. About 0.15 million women in Chin repo. Jly have the MRKH syndrome [1]. The main . ical mar, iestation in patients is primary amenorrhea and vareunia, while the vast majority of patients have norma ovarian function, good physical and intelle 1 leve'opment, with the development of typical fomale ordary sex characters and psychology. The rinc le ain of treating the congenital absence of vagina

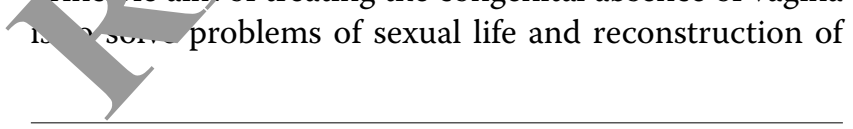

*Correspondence: leaiwen19@126.com

${ }^{1}$ Department of Obstetrics and Gynecology, Affiliated Shenzhen

Nanshan People's Hospital of Guaongdong Medical University,

Shenzhen 518052, Guangdong, China

Full list of author information is available at the end of the article vagina. Currently, there are several methods for vaginal reconstruction. According to the American Congress of Obstetricians and Gynaecologists (ACOG), self-dilation is still the therapy of first choice. It applies to patients with a vaginal shallow fossa over $2.5 \mathrm{~cm}$, with complications such as urinary tract infection, urinary fistula secondary prolapsed [2]. For patients having poor compliance, the indications should be strictly controlled [3-6]. Laparoscopic-assisted Vecchietti technique is the method for patients whose vulva is well developed and urethral mouth is located in the higher parts of the vestibule. The Vecchietti vaginoplasty technique is not effective if vaginal vulva conditions are poor [7-10].

Reconstructive surgeries using the sigmoid colon or ileum are common and provide satisfactory results [11]. But this method has the following disadvantages such as its complex procedure, there is a possibility of intestinal complication due to the large intestinal cavity, and the 
secretion smells bad early after operation, postoperative artificial vaginal prolapse and stenosis [12, 13]. Laparoscope-assisted surgery is superior to laparotomy as it is not complicated and does not involve the risk of large incision or serious bleeding and the incidence of postoperative pelvic adhesion is less. Laparoscopic peritoneal vaginoplasty provides a fully exposed surgical field, maintains a relatively stable environment in the pelvic cavity, reduces the risk of pelvic, provides cosmetically acceptable abdominal incisions, and alleviates psychological stress for patients $[14,15]$. The traditional laparoscopic peritoneal vaginoplasty, also known as the Luohu I operation, was first performed by Dr. Luo Guangnan, a Professor in Shenzhen Luohu District People's Hospital, in 1998 [16]. A previous work suggested this operation should generally be performed on patients older than 18 years. However, it may be performed as early as possible if younger patients have a normal uterus and are suffering from periodic hypogastralgia or menstrual disorders [16].

A modified form of the operation, Luohu II, was developed later. In the present study, the surgical outcomes of the Luohu I and Luohu II operations are compared to understand the advantages and disadvantages so as improve the curative effect of surgery in the future

\section{Methods}

\section{Subject characteristics}

Informed consent was received from the $\mathrm{P}$ ints who participated in the study; the stud f was app, ved by the hospital ethics committee. Pat ents with the MRKH syndrome who underwent either $t$ Luoh $A$ I or Luohu II operations in affiliated Shenzher _...unshan People's Hospital and affiliated Shenz $\ldots$ ho tal, Guang don Medical Colleg were recruited between November 2001 and De embel 2012. All the patients were unmarried. A no patients were enrolled with a mean a of $20 \pm 2.9$ years. No abnormalities were ide $1 \mathrm{t}$. during the preoperative gynecologic examinations, and the patients had normally developed vy va The depth of vaginal vestibules ranged from $1.6 \pm 0$. n. T) e ultrasonic examination revealed norm red o es. However, 291 patients had a rudimenry torus and 9 patients had an infantile uterus. All $\mathrm{pa}$ nts enrolled had normal karyotypes (46XX).

\section{Surgical procedure}

Patients were prepared using the established standard of care for laparoscopic surgery. The bowel was prepared 3 days prior to the operation, and oral intestinal antibiotics were prescribed. Patients were instructed to consume a no-residue diet the day before the surgery and made to fast for $12 \mathrm{~h}$ prior to the surgery. They were given a cleansing enema prior to the surgery. Surgery was carried out under intravenous anesthesia with endotracheal intubation. Patients were placed in the head-low hip-high lithotomy position.

All patients had two $10-\mathrm{mm}$ trocars inserted, one through the umbilical site and the other th. "or incision at McBurney's point. A third trocar (an) was inserted through an incision in th 'oft low abdomen. The laparoscope was used to exa' nint a pe' vic cavity to evaluate the rudimentary uter as, connec, e tissue cords, bilateral ovaries and oviducts elaxatign of the perineum, and location of the anter $r$ re extent and location of the $\mathrm{d}$ der rectum lacunae.

\section{Luohu ll operation.}

A total of 15 tients iderwent the Luohu II operation. A pur ture needle (size 22, without a needle core) for epidural estnesia was inserted through the gap betwean the blay er and rectum toward the peritoneum beyona th cord. A total of $200 \mathrm{ml}$ of physiological saline solation containing $6 \mathrm{U}$ of pituitrin and $0.1 \mathrm{ml}$ of epinephri, ie were injected to form a water cushion. The shion was expanded until the peritoneum became thin an white, and was bulging toward the pelvic cavity. The ncedle was withdrawn slowly, while the fluid was being injected to ensure that the gap was filled with the solution. A pair of medium-sized, curved pliers was inserted through the vaginal vestibule mucosa to divide the gap between the bladder and rectum. This formed a vaginal tunnel that could accommodate approximately 2-3 fingers and that extended to the pelvic extraperitoneal region. During the procedures, a suction flusher was used for the formation of the vaginal tunnel from the pelvic peritoneum posterior to the fiber cord to the peritoneum at the vaginal vestibule. A mold (size 1) (Fig. 1), $2.2 \mathrm{~cm}$

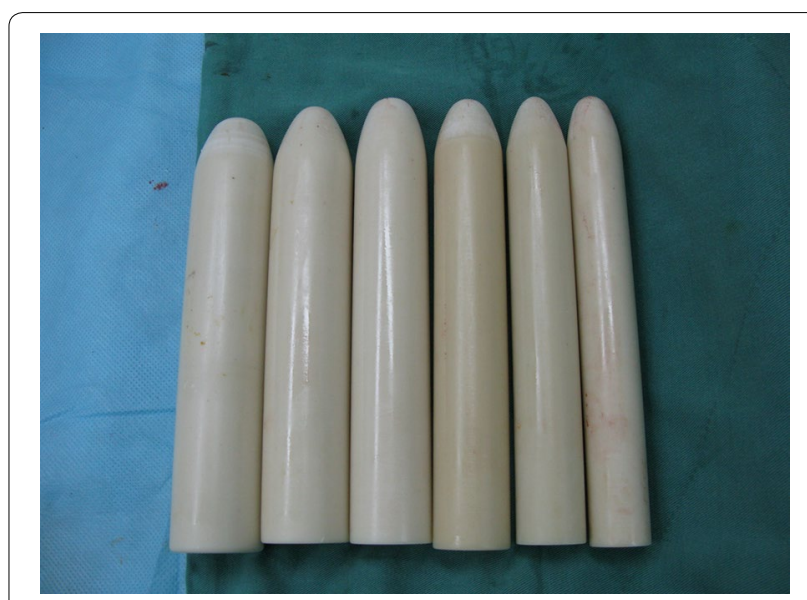

Fig. 16 vaginal dilatation rods (mold) whose diameters are 2.2, 2.5, $2.8,3.0,3.3,3.5 \mathrm{~cm}$, length is $20 \mathrm{~cm}$ (use in operation) 
in diameter, was inserted through the tunnel to push the bladder upward and form a bulge in the peritoneum. Near the end of the first mold, the peritoneum and tissues at the bottom of the pelvic cavity were incised to create a tunnel connecting the vaginal vestibule and the abdominal cavity. A second mold (size 2-6, 2.5-3.5 cm in diameter) was used to gradually dilate the tunnel. Once the tunnel was dilated, the peritoneum was pushed downward through the tunnel. The peritoneum layer formed the inner surface covering the vaginal tunnel and making the artificial vagina. An absorbable thread (size $3 / 0$ ) was used to suture the peritoneum and mucosa at the vaginal vestibule at four points. A purse-string suture was made along the fiber cord, peritoneum at the pelvic wall, anterior rectal wall at the same level, and bilateral perirectal ditches using non-absorbable thread (Fig. 2). A mold was placed to hold the vaginal tunnel in shape and the vaginal opening was sutured to avoid the mold slipping, The vaginal mold was made of $5 \mathrm{~m}^{2}$ iniector outsourcing vaseline gauze sheathed with $3 \mathrm{H} r$, con toms (Fig. 3).

\section{Luohu I operation}

Clinicians designed a custo $n$ peritons 1 push rod of $55 \mathrm{~cm}$ in length and $1.8 \mathrm{~cm}$ in diam ter for use in the Luohu I operation. The gle wern the head $(1.8 \mathrm{~cm})$ and the body of the ush d was $30^{\circ}$. A $10-\mathrm{cm}$ metal stick $(0.5 \mathrm{~cm}$ diam $r)$ was in rted into a hole of $10 \mathrm{~cm}$

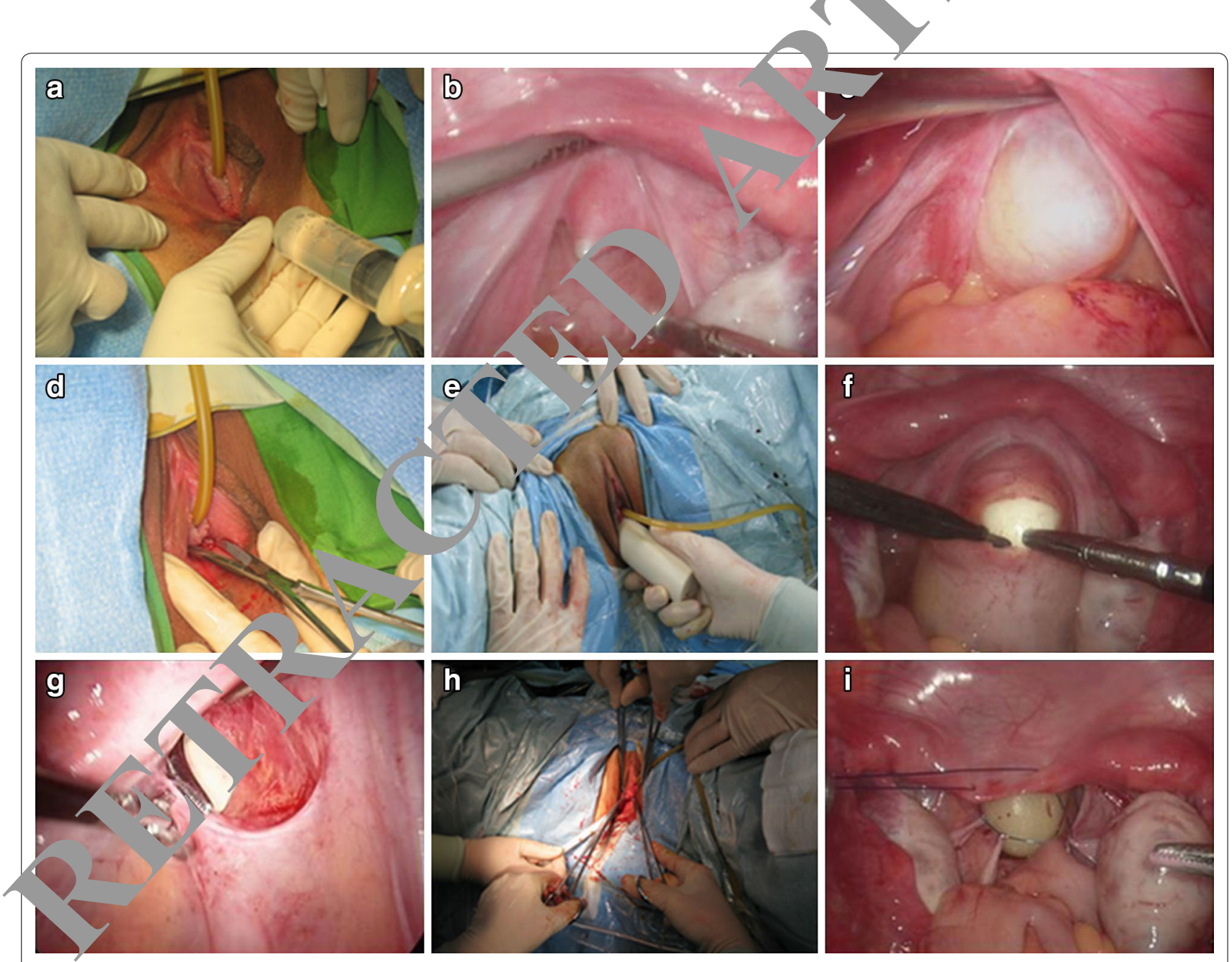

Fig. 2 a A puncture needle for epidural anesthesia connected to a $20 \mathrm{ml}$ syringe inserted through the middle of the vaginal vestibule. b The puncture needle inserted through the gap between the bladder and the rectum toward the peritoneum beyond the fiber cord. c The water cushion formed by injecting physiological saline solution containing pituitrin and epinephrine. The cushion helps to divide the peritoneum at the pelvic floor and rectum. d The vestibule mucosa divided using medium-sized, curved pliers. Then the vaginal tunnel is formed by extending the incision using the clinician's finger. e A mold inserted through the vaginal tunnel. f The peritoneum at the end of the mold incised using an electric scalpel. The incision is extended by the mold and a larger mold is used to dilate the vaginal tunnel. $\mathbf{g}$ The clinician guiding the peritoneum downward using his finger on the incision margin of the peritoneum as a guide toward the vaginal opening by the pliers. $\mathbf{h}$ The vaginal opening sutured at four points (3, 6, 9, and 12 o'clock). i A mold being put in the vaginal tunnel and purse-string sutures used to close the pelvic cavity 


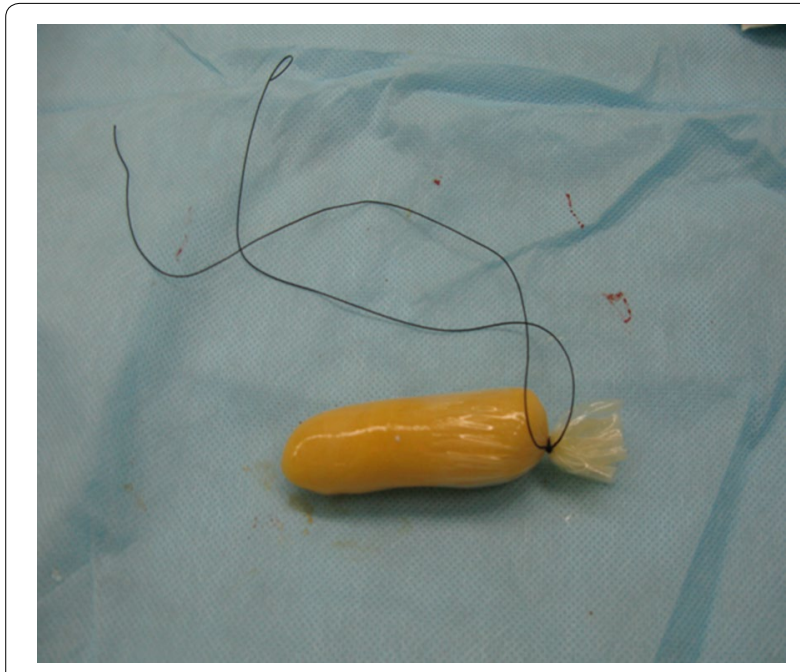

Fig. 3 vaseline gauze wrapped mold

from the end of the rod to help manipulate the push rod and keep the head of the rod upward.

The water cushion and vaginal tunnel were formed described above. The vaginal tunnel was dilated us the index and middle fingers of the clinician as des nibea for the Luohu II operation. The push rod was inserted instead of the molds to push the peritoneum do vard. In brief, the laparoscope was inserted thro oh the $t_{1}$ ar at the McBurney point. After the troc $\mathrm{r}$ a , umbilical site was withdrawn, the incision was exte $c$ do a length of $18 \mathrm{~cm}$ through which the ustom-designed peritoneal push rod was inserted into e abdominal cavity. The push rod was manipulated by th. . icians through the vaginal tunnel to push th peritoneum at the
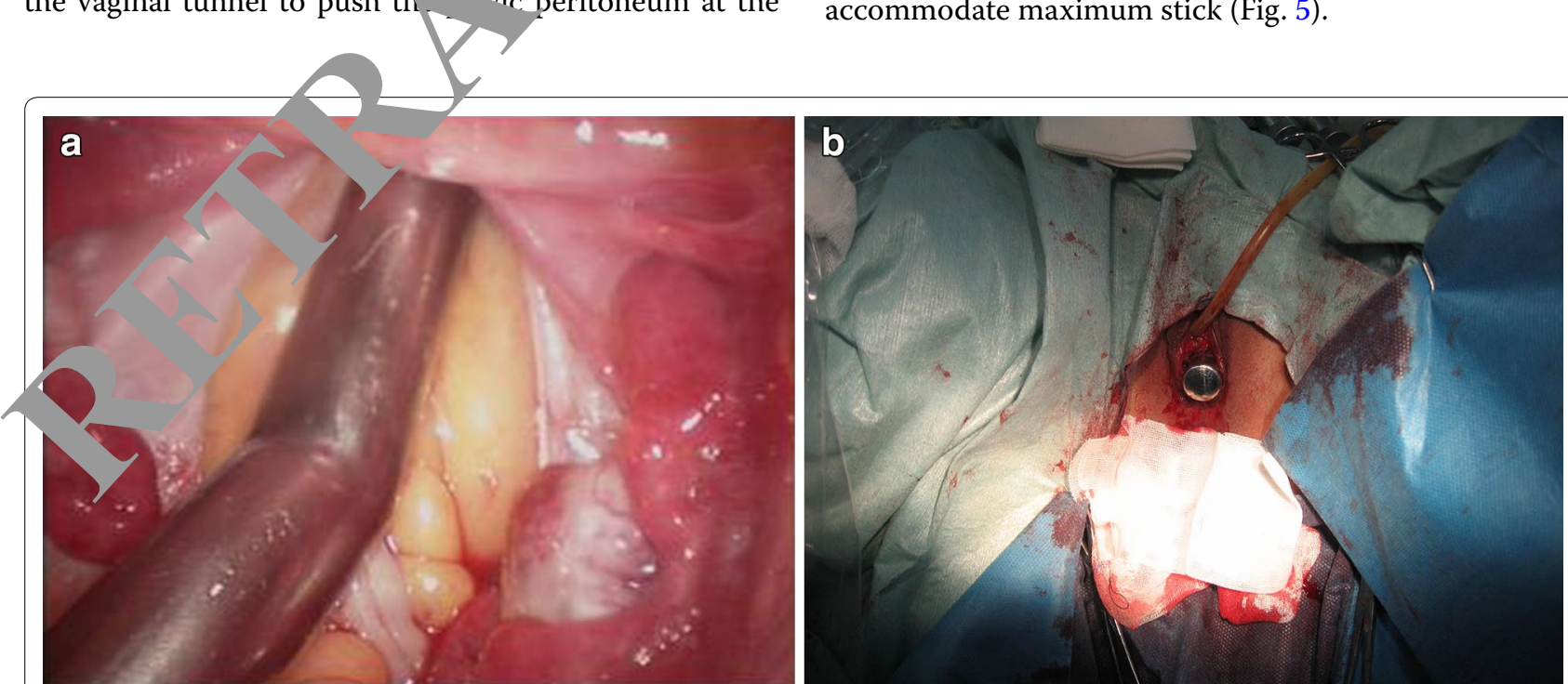

Fig. 4 The clinician forcing the rod through the vaginal tunnel to push the pelvic peritoneum at the bladder rectum lacunae toward the vaginal opening bladder rectum lacunae toward the opening of the tunnel at the vaginal vestibule. The operation was then completed as described for the Luohu II operation (Fig. 4).

\section{Postoperative treatment}

The patients were given a 5-day course or tory drugs. In addition, the patients were ask tos scrub the perineum using Iodophor $(0.1$ ) twice daly which started at 9 am and $5 \mathrm{pm}$, each t' $\mathrm{me}$ tained $15 \mathrm{~min}$. A liquid diet was provided for $\mathrm{t}^{\mathrm{l}} \mathrm{e}$ patients $\mathrm{n}$ post-surgery and they returned to normal iet after being able to pass gas. The patients were "ow $n$ mbulate $24 \mathrm{~h}$ postsurgery, and the cathe er w removed $48 \mathrm{~h}$ post-surgery. There were not sy "ling rea hd swollen, exudation in vulva vagina for "rec ry" 10 days post-surgery. After recovery, the tures wie removed and the vaseline gauze wrar $\mathrm{od}$ ald was removed from the vaginal tunnel. The pati $s$ were asked to rinse the vaginal tunnel with Indophor $.1 \%$ ) 1-2 times per day and dilate the tunnel row wers wearing sterile gloves at 10-13 days post-sur.ery. A mold with $2.2 \mathrm{~cm}$ diameter was used to dilate the vaginal tunnel once daily for 14-30 day postgery (Fig. 5). Gradually the mold was switched to one w. I a $2.5-2.8 \mathrm{~cm}$ diameter to dilate the vaginal tunnel 2. 3 times/day for 60 days post-surgery. The patients were asked to learn how to dilate the tunnel themselves and were allowed to have sex and were surveyed about sexual satisfaction at the 90th day post-surgery.

Sexual life quality was checked by Female Sexual Function Index (FSFI), The total score is 36 points, dissatisfaction is below 23.45 in china [17]. The length was distance between the vaginal orifice and posterior fornix by vaginal expansion stick; the width was the diameter of accommodate maximum stick (Fig. 5). 


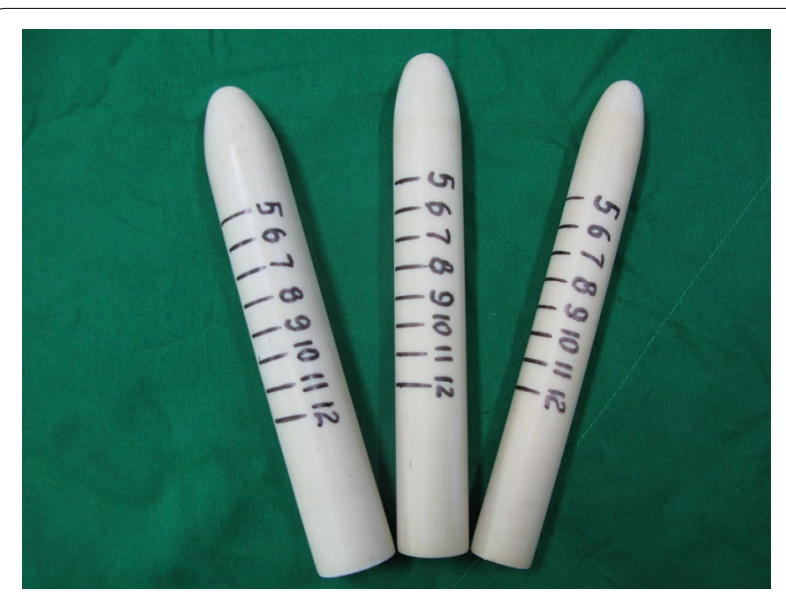

Fig. 53 vaginal dilatation rods (mold) which diameters are 2.2, 2.5, $2.8 \mathrm{~cm}$, length is $20 \mathrm{~cm}$ (use after operation)

\section{Statistical analysis}

SPSS 13.0 software was used for the statistical analysis. Quantitative data were presented as the mean \pm SD. The student $t$ test and $\chi^{2}$ test were used to appropriately com pare the two groups. Results with $\mathrm{P}<0.05$ were con ered statistically significant.

\section{Results}

\section{Operation time and intraoperative blood los}

There was no significant difference in the mo operation time and the mean intraoperative blod loss ame in the two groups.

\section{Time to gas passage, hospital stay}

There was no significant dift in the meantime to gas passage or the mean hospit l stay for the two groups.

\section{Complications}

All 155 patients in the ohu II group were successfully treated. How rectal 1, jury was found in one patient (incidence race: $0 . \%$ ) during the operation. The injury was imrediately repdired and the vaginoplasty was completed tr._pa ient.

In the Lu $\mathrm{u} /$ group, six patients developed complica+ ons uring or post-surgery. The incidence rate (4.14\%) was significantly higher in the Luohu I group than in the Luohu II group. The complications fell into two classes, peritoneal rupture during the operation $(\mathrm{N}=3)$ and anterior rectum wall injuries $(\mathrm{N}=3)$. In the patients with peritoneal ruptures, the margin of the rustured peritoneum was pulled down through the vagı unn sutured with the vaginal opening. In all thi nutients, the Luohu I operation was then $c$ pleted successfully. The majority of the injuries to the a rior rectum wall occurred during the surgery. They occu ed while making the crucial incision on e perity neum by the end of the push $\operatorname{rod}(\mathrm{N}=1)$ and divion of the anterior rectum wall during $t^{\text {the to }}$ to ation of the vaginal tunnel $(\mathrm{N}=2)$. To repair anterı rectum wall division, the injury was sutur $d p_{1}$ to continuing to push the peritoneum dowr $\mathrm{d}$ in $\mathrm{th}_{\mathrm{l}}$ Luohu I operation. If a rectal injury occ red uring the surgery, it was immediately repaired $(\mathrm{N}$ ). In rectal injuries were identified postsurger the rec vaginal fistula was repaired 6 months post-sury $y=1$ ).

\section{Follow-up, tudy}

e patients were followed up for 3-12 months postsu jery. It included following items in every follow-up: le, gth and width of vaginal, having sex life or no, sex life quality, vaginal discharge, defecation, and so on. The vaginas were in good condition and the vaginal speculumassisted examination was possible. The vaginal mucosa was pink, moist, and had good elasticity. The length of the vagina for patients in both groups was approximately $9.18 \pm 1.27 \mathrm{~cm}$ and the width was $2.82 \pm 0.73 \mathrm{~cm}$ postoperative 3-12 months (Table 1).

The majority of patients chose to have sexual relations, including 148 patients who underwent the Luohu II procedure and 138 patients who underwent the Luohu I procedure.

Sexual satisfaction was checked by Female Sexual Function Index (FSFI). A total of 140 patients from the Luohu II group were satisfied with the sexual experience, and 129 patients from the Luohu I group reported satisfaction. The difference in sexual satisfaction was not significantly different between the two groups. The patients with dissatisfaction included those having vaginal stenosis and too short, early having sex post-surgery.

Table 1 Situation comparison of operation and post operation in two groups

\begin{tabular}{lllllll}
\hline Group & $\begin{array}{l}\text { Operation } \\
\text { time (min) }\end{array}$ & $\begin{array}{l}\text { Blood } \\
\text { loss }(\mathrm{ml})\end{array}$ & Complication & $\begin{array}{l}\text { Time to gas } \\
\text { passage (h) }\end{array}$ & $\begin{array}{l}\text { Hospital stay } \\
\text { (day) }\end{array}$ & $\begin{array}{l}\text { Vagina length/ } \\
\text { width (cm) }\end{array}$ \\
\hline$\|$ & $65.38 \pm 14.36$ & $27.34 \pm 14.68$ & $1 / 155$ & $14.65 \pm 8.96$ & $9.05 \pm 2.12$ & $9.58 \pm 1.25 / 2.75 \pm 0.6$ \\
satisfaction
\end{tabular}




\section{Discussion}

Several widely used surgical methods are available to treat the MRKH syndrome which includes amniotic membrane vaginoplasty, vulvar skin flap vaginoplasty, skin graft vaginoplasty, intestinal vaginoplasty, autologous tissue vaginoplasty and peritoneal vaginoplasty [18-22]. The sigmoid colon vaginoplasty has several disadvantages including long operation time, serious trauma, and an unpleasant smell [23]. Patients who have undergone bladder vaginoplasty have been reported with a long-term lower urinary tract infection [24]. Currently, it is difficult to achieve a breakthrough in obtaining a large number of seed cells [25].

The peritoneum is soft, moist, has good elasticity, and is similar to normal vaginal mucosa in function and form. The smooth surface and its ability to secrete mucus, defend, and undergo self-repair making it a promising cover for an artificial vagina [26, 27].

Luohu II is a modification of the original surgical procedure, Luohu I. The results had shown no significant differences in the operation time, intraoperative blood loss, time to gas passage, hospital stay, and vaginal depth between the two procedures. The primary difference between the two procedures is that the modified pi cedure, Luohu II, uses molds, rather than a push. od, to push the peritoneum downward. The vaginal $c$ var sion stick expands the vaginal tunnel, reducing bed. and avoiding damage to the rectum and blad $r$. The ro al injuries are the most common injuries urin vaginoplasty. It has been found that the in riaence of 0 mplications was lower with the modifie Luohu II procedure and that the formation of vaginal nnel is the critical issue during every vaginoplacty. In tin Luohu II procedure, the water cushion and $\mathrm{t}_{\mathrm{in}} \mathrm{d}_{3} \mathrm{used}$ to manipulate the peritoneum heln to de rease the risk of injuries to the rectum, bladd $\mathrm{r}$ an ureth a than Luohu I. Indeed, in the present study, nce of injury in the Luohu II group was sig lificant, wer in Luohu II group than in Luohu I grov $p$.

Laparos opic per real vaginoplasty forms an artificial vagina ith an acidic microenvironment covered by an inner Ta, or sq amous epithelial cells 5-6 months postsu $y$. In . ly ways, the results are similar to a normal gin The artificial vagina created during a peritoneal va. oplasty is very smooth, moist, and has good elasticity. the length and width of the vagina for patients in both groups was similar to normal vagina. FSFI can not only evaluate the severity of FSD(female sexual dysfunction) but also provide the basis for FSD classification. FSD is influenced by the cultural, racial and other factors. The sexual dissatisfaction is less than 23.45 points in China; the rate of satisfaction was high in two groups. The laparoscopic peritoneal vaginoplasty has several advantages over other surgical options including small incisions, speedy recovery and an artificial vagina that is highly elastic. These traits make it a promising surgical method for treating the MRKH syndrome.

To avoid stenosis, the patients should ase molds to dilate the vaginal tunnel regularly after su $\mathrm{row}_{\mathrm{W}}$ men were able to engage in sexual intercourse $3 \mathrm{~m}$ th postsurgery, which could also dilate the nginal tunnel. However, patients should be aware that $s$ 'senerally form within 1-month post- surger. Most of sears vanish by 3 months post-surgery. Tc nsure aldequate width and depth, the vaginal tunn sho ho dilated with molds for more than 3 mont $^{1}$. In e present study, the patients were reexamined at 3,6 , an, 2 months post-surgery.

In summary, the Lu II laparoscopic peritoneal vaginoplasty is an ective a d simple surgical method. The keys to avo the niurv of the anterior wall of the rectum are to push tum through water pressure and expand fully the vagina annel by vaginal expansion stick, the patient on dilate the vaginal tunnel regularly after surgery by molds and engage in sexual intercourse 3 months post-surgery preventing from vaginal stenoThis method is not suitable for patients who have a lit ted area of pelvic floor peritoneum, have previously urdergone operations in the pelvic cavity, or who have a nistory of pelvic adhesions [28, 29]. However, surgeons must still be aware of how to perform other surgical procedures for vaginoplasty in case the intended procedure fails. The first recommended way is laparoscopic vaginoplasty using sigmoid colon for cases where the previous operation was a failure [30-32]. The William technique is suitable in case of the vagina operation failure, pelvic radical operation or radiotherapy, and the vulva development is good without urethral dilatation [33].

\section{Authors' contributions}

AL participated in the design of the study and performed the statistical analysis. ZW conceived of the study, and participated in its design and coordination and helped to draft the manuscript. LS and GL participated in clinical search.

TX and RZ participated in acquisition. All authors read and approved the final manuscript.

\section{Author details}

${ }^{1}$ Department of Obstetrics and Gynecology, Affiliated Shenzhen Nanshan People's Hospital of Guaongdong Medical University, Shenzhen 518052 , Guangdong, China. ${ }^{2}$ Department of Obstetrics and Gynecology, Affiliated Shenzhen Luohu People's Hospital of Guaongdong Medical University, Shenzhen 518052, Guangdong, China.

\section{Acknowledgements}

This work was supported by operation room and Ultrasound departments. We appreciate the valuable comments from other members of our hospital. Research supported by a grant from the Research Funding: Shen zhen city technology creative committee. No: JCYJ2014041109115144.

\section{Compliance with ethical guidelines}

\section{Competing interests}

The authors declare that they have no competing interests. 
Received: 28 January 2015 Accepted: 14 August 2015

Published online: 22 August 2015

\section{References}

1. Zhu L, Wong F, Lang JH. Female genital abnormalities of minimally invasive surgery and map. Beijing: Peoples Health Press; 2010.

2. Liao L, Doyle J, Crouch NS, Creighton SM. Dilation as treatment for vaginal agenesis and hypoplasia: a pilot exploration of benefits and barriers as perceived by patients. J Obstet Gynaecol. 2006;26:144-8.

3. Ismail-Pratt IS, Bikoo M, Liao LM, Conway GS, Creighton SM. Normalization of the vagina by dilator treatment alone in Complete Androgen Insensitivity Syndrome and Mayer-Rokitansky-Kuster-Hauser Syndrome. Hum Reprod. 2007;22:2020-4.

4. Creatsas G, Deligeoroglou E, Makrakis E, Kontoravdis A, Papadimitriou L. Creation of a neovagina following Williams vaginoplasty and the Creatsas modification in 111 patients with Mayer-Rokitansky-Kuster-Hauser syndrome. Fertil Steril. 2001;76:1036-40.

5. Lee MH. Non-surgical treatment of vaginal agenesis using a simplified version of Ingram's method. Yonsei Med J. 2006;47:892-5.

6. Morcel K, Lavoué V, Jaffre F, Paniel BJ, Rouzier R. Sexual and functional results after creation of a neovagina in women with MayerRokitanskyKüster-Hauser syndrome: a comparison of nonsurgical and surgical procedures. Eur J Obstet Gynecol Reprod Biol. 2013;169:317-20.

7. Csermely T, Halvax L, Sorkany A. Sexual function after modified laparoscopic Vecchietti's vaginoplasty. J Pediatr Adolesc Gynecol. 2011;24:147-52.

8. Miller PB, Forstein DA. Creation of a neovagina by the Vecchietti procedure in a patient with corrected high imperforate anus. JSLS 2009;13:221-3.

9. Kdous M, Chaker A, Ferchiou M, Zhioua F. The laparoscopic Vecch technique for vaginal agenesis. Tunis Med. 2013;91:371-5.

10. Abramowicz S, Oden S, Joutel N, Roman H, Gromez A, Marp roscopic creation of a neovagina by Vecchietti's techniqu ana functional results. Gynecol Obstet Fertil. 2013;41:4-9.

11. Nakhal RS, Creighton SM. Management of vaginal a ge $\mathrm{e}$ Pediatr) Adolesc Gynecol. 2012;25:352-7.

12. El-Sayed HM, El-Lamie IK, Ibrahim AM. Vaginat, ecconstruction ith sigmoid colon in vaginal agenesis. Int Urog necol J Pelvic Floor Dysfunct. 2007;18:1043-7.

13. Imparato E, Alfei A, Aspesi G, Meus AL, Spini Yona-erm results of sigmoid vaginoplasty in a consecutive series of 62 , _....nts. Int Urogynecol J Pelvic Floor Dysfunct. 2007;8:1465-

14. Shi L, Ming D, Keke X, Chun ping W, Xe fe, iy Juan Juan, Guan nan L. Laparoscopic peritor- vagino, rasty. Chin J Obstet Gynecol. 2003;38:312-3.

15. Shi L, Ming Zh, Guann et oscopic peritoneal vaginoplasty versus sigmoid los, vagin. "asty: a comparison study. Chin J Min inv Surg. 2005;5:65

16. Luo GN. Vagi iop Beijing: People military surgeon publishing company; 2009 .

17. Ma J, P $\cap$ IL, Lei $Y$, Zhang A, Kan Y. Prevalence of female sexual dysfunction in ur a Cinesewomen based on cutof scores of the Chinese version of the ale sexu y function index:a preliminary study[J]. J Sex Med.
18. Davies MC, Creighton SM. Vaginoplasty. Curr Opin Urol. 2007;17:415-8.

19. Alessandrescu D, Peltecu GC, Buhimschi CS, Buhimschi IA. Neocolpopoiesis with split-thickness skin graft as a surgical treatment of vaginal agenesis: retrospective review of 201 cases. Am J Obstet Gynecol. 1996;175:131-8

20. Ugur MG, Balat O, Ozturk E, Bekerecioglu M, Dikensoy E, Mtralls in diagnosis and management of distal vaginal agenesis: 10-ye exprience at a single centre. Eur J Obstet Gynecol Reprod Biol. 2012,

21. Prakash $V$. Triple flap vaginoplasty for agenesis of the vag Gynaecol Res. 2011;37:501-4.

22. Schober JM. Cancer of the neovagina. J Pean Yrol. 200 3:167-70.

23. Khen-Dunlop N, Lortat-Jacob S, Thibaud ' Clen 'Zizz M, Lyonnet S, Nihoul-Fekete C. Rokitansky syndror e: clinical exp ence and results of sigmoid vaginoplasty in 23 your girls. The Jqurnal of urology. 2007:177:1107-11.

24. Borkowski A, Czaplicki M, Do nski years of experience with Krzeski's cystovaginoplas wor wal agenesis in Mayer-Rokitansky-Küster-Hauser syr rrome: ana ical, histological, cytological and functional results. B O 2008;101:1)+33-40.

25. Dessy LA, Mazzoca i M, $\mathrm{C}$ F, Ceccarelli S, Marchese C, Scuderi N. The use of cultured ologous o epithelial cells for vaginoplasty in maletofemale tran sexuc a feasibikty, safety, and advantageousness clinical pilot stuary st surg. 2014;133:158-61.

26. Jo EJ, Lee YY, TJ, Choi CH, Lee JW, Bae DS, Kim BG. Management and outcome of recta jury during gynecologic laparoscopic surgery. J Min rive Gynecol. 2013;20:166-71.

27. Clear RKy Mu erantz RA, Lampman RM. Colon and rectal injuries. Dis Colon ectum. 2006;49:1203-22.

28. Mariano /ski P, Kaminski P, Wielgos M, Szymusik I, Ludwikowski G. The comparison of microlaparoscopy and laparoscopy in pelvic region assessment in infertile women. Neuro Endocrinol Lett. 2007;28:704-7.

29. Allen LM, Lucco KL, Brown CM, Spitzer RF, Kives S. Psychosexual and functional outcomes after creation of a neovagina with laparoscopic Davydov in patients with vaginal agenesis. Fertil Steril. 2010;94:2272-6.

30. Nowier A, Esmat M, Hamza RT. Surgical and functional outcomes of sigmoid vaginoplasty among patients with variants of disorders of sex development. Int Braz J Uro. 2012;38:380-8.

31. Carrard C, Chevret-Measson M, Lunel A, Raudrant D. Sexuality after sigmoid vaginoplasty in patients with MayerRokitansky-Küster-Hauser syndrome. Fertil Steril. 2012;97:691-6.

32. El-Sayed HM, El-Lamie IK, Ibrahim AM, El-Lamie KI. Vaginal reconstruction with sigmoid colon in vaginal agenesis. Int Urogynecol J Pelvic Floor Dysfunct. 2007;18:1043-7.

33. Creatsas G, Deligeoroglou E, Makrakis E, Kontoravdis A, Papadimitriou L. Creation of a neovagina following Williams vaginoplasty and the Creatsas modification in 111 patients with Mayer-Rokitansky-Küster-Hauser syndrome. Fertil Steril. 2001;76:1036-40.

\section{Submit your next manuscript to BioMed Central and take full advantage of:}

- Convenient online submission

- Thorough peer review

- No space constraints or color figure charges

- Immediate publication on acceptance

- Inclusion in PubMed, CAS, Scopus and Google Scholar

- Research which is freely available for redistribution

Submit your manuscript at www.biomedcentral.com/submit
C Biomed Central 